\title{
Correlation between E-Cadherin and Hormone Receptor Status among Breast Cancer Patients
}

\author{
Anusha Hassan Ali, Ghulam Haider, Khalil Ahmed, Madiha Hashmi, Perwasha Kerio and Razia Irshad \\ Department of Medical Oncology, Jinnah Postgraduate Medical Centre, Karachi, Pakistan
}

\begin{abstract}
Objective: To determine the association between E-cadherin expression and hormone receptors status in patients with breast cancer.

Study Design: Cross-sectional study.

Place and Duration of Study: Department of Medical Oncology, Jinnah Postgraduate Medical Centre, Karachi, Pakistan, from March to December 2019.

Methodology: Two hundred and forty-eight women, aged 18-65 years with histologically proven diagnosis of breast carcinoma, were included in the study. Immunohistochemistry (IHC) staining was performed for the evaluation of E-Cadherin expression and status of hormonal receptors [Estrogen receptor (ER), Progesterone receptor (PR) and HER-2-neu]. The positive homogeneous pattern of staining for the cellular membranes is considered normal. The non-homogeneous or the heterogeneous pattern of the cytoplasm and membrane, represented aberrant E-cadherin expression (loss of E-cadherin expression). SPSS version 23 was used to analyse data.

Results: The results of IHC showed that $82.7 \%$ of the tumours were E-cadherin positive, $65.7 \%$ were ER positive, $62.9 \%$ were PR positive and $29.4 \%$ were HER 2 positive. A normal pattern of immunostaining of E-cadherin for the membranes is seen in hormone receptor positive and young patients with low grade tumour. Aberrant E-cadherin expression (loss of E-Cadherin)was noticed in HER 2 negative, postmenopausal women with high grade large size tumour $(p<0.05)$.

Conclusion: The study showed that there is significant association between $\mathrm{E}$-cadherin expression and hormone receptor status, HER2-neu, menopausal status, age of patients, grade of tumour and size of tumour.
\end{abstract}

Key Words: E-cadherin, Hormone receptors, Breast carcinoma, ER, PR and HER 2.

How to cite this article: Ali AH, Haider G, Ahmed K, Hashmi M, Kerio P, Irshad R. Correlation between E-Cadherin and Hormone Receptor Status among Breast Cancer Patients. J Coll Physicians Surg Pak 2020; 30(10):1030-1034.

\section{INTRODUCTION}

$\mathrm{E}$-cadherin is a protein that is present in the epithelial tissues of breast. It is encoded by $\mathrm{CDH} 1$ gene. It is significant in maintaining adhesion between cells of epithelium and responsible for transition between mesenchyme and epithelium. It possesses tumour suppressing properties. Loss of E-cadherin may result in invasion and distant metastasis. ${ }^{1,2}$ Breast cancer is ranked as second most common cancer globally; and reported as $25 \%$ of all the cancers. ${ }^{3}$ Despite availability of wide variety of treatments like chemotherapy, surgery, radiotherapy, endocrine therapy, targeted therapy and immunotherapy, breast cancer prognosis and treatment still seem to be very challenging. ${ }^{4}$ Pakistan is ranked highest among Asian countries in breast cancer incidence. $^{5}$

Correspondence to: Dr. Anusha Hassan Ali, Department of Medical Oncology, Jinnah Postgraduate Medical Centre, Karachi, Pakistan

E-mail: hakroali@gmail.com

Received: June 15, 2020; Revised: September 22, 2020;

Accepted: October 17, 2020

DOI: https://doi.org/10.29271/jcpsp.2020.10.1030
E-cadherin loss is mainly coupled with non-cohesive and invasive pattern in invasive carcinoma of breast. It is still ineffectively comprehended that E-cadherin loss is associated with phenotype of invasive lobular carcinoma. There is an ongoing debate regarding loss of E-cadherin, including the deactivation of $\mathrm{CDH} 1$, which is typically the loss of heterozygosity on chromosome $16 \mathrm{q}$, transcriptional deactivation and homozygous erasure. ${ }^{6} \mathrm{E}$-cadherin is a kind of cell bond glycoprotein. It not only inhibits invading of cancerous cells, but also metastasis. ${ }^{7}$ It is a typical inhibitor of cell development. When epithelial-mesenchymal progress happens in malignant cells, E-cadherin diminishes or shows malfunction, consequently causing diminished loss of extremity and invasion of the encompassing tissue development and cell bond. It might spread to different organs of the body like liver, bone, lung or brain. ${ }^{8}$

There are different investigations that are used to confirm breast cancer (histological type, grade of tumour, lymph node status, tumour size, human epidermal growth factor receptor-2 (HER-2), estrogen receptor (ER), and progesterone receptor (PR). ${ }^{9}$ Even with multiple investigations, the prognosis remains vague and is not able to predict the survival of patients with breast cancer. ${ }^{10}$ Therefore, it is crucial to explore new parameters that help predict survival of breastcancer patients. The down regulation of 
E-cadherin is reported to be associated with poor outcomes in breast cancer patients and hence survival rate is not higher. ${ }^{11}$ Therefore, it is very imperative to determine the role of E-cadherin among breast cancer patients. Nonetheless, the correlation of E-cadherin with hormone receptor status is still of great value. Hence, the aim of this study was to evaluate the association between $\mathrm{E}$-cadherin and hormone receptor status.

\section{METHODOLOGY}

It was a cross-sectional survey conducted at the Department of Medical Oncology, Jinnah Postgraduate Medical Centre, Karachi, Pakistan, from March to December 2019. Sample size of 248 patients with breast cancer was estimated using open EPI-online sample size calculator by taking statistics for the positive expression rate of E-cadherin as $36.44 \%$ in invasive ductal carcinoma (IDC) of breast cancer, margin of error was $6 \%$ and confidence interval $95 \%{ }^{12}$ All the females of age $18-65$ years with histologically proven diagnosis of breast carcinoma were included in the study. The females with breast cancer and pregnant, were excluded.

The Ethical Review Committee approval was taken before conduction of the study and informed consents from all the eligible patients were obtained before collection of data. Sociodemographic data along with clinicopathological features and medical history were noted on predesigned proforma.

Immunohistochemistry (IHC) staining wasperformedfortheevaluation of E-Cadherin expression and status of hormonal receptors [Eestrogen receptor (ER), progesterone receptor (PR) and human epidermal growth factor receptor 2 (HER-2-neu)]. The expression of HER-2 was confirmed by the technique of fluorescent in situ hybridization (FISH) in those patients which had equivocal result on immunohistochemistry (IHC). E-cadherin expression was examined semi-quantitatively by proportion of membrane-positive cells: 0 (0 to $10 \%) ; 1+(10$ to $30 \%) ; 2+(30$ to $70 \%) ; 3+(>70 \%) \cdot 13,14$ The expression of E-cadherin was deemed positive, if the score was $\geq 2$; and negative, if the score was $\leq 1$.

SPSS version 23 was used to analyse data. Mean and SD values were computed for numeric variables. Frequencies and percentages were computed for categorical and nominal variables. Chisquare test was applied to see the association between E-Cadherin expression and hormone status. Further, E-Cadherin expression was also stratified with respect to age and clinicopathological features, using Chi-square test. A $p$-value $\leq 0.05$ was considered as statistically significant.

\section{RESULTS}

The mean age of the females with breast cancer was $47.88 \pm 12.58$ years. Majority of the females were married $(82.3 \%)$, Unemployed $(92.3 \%)$, had negative family history of breast cancer ( $88.3 \%)$; and almost half of the females had pre-menopausal status $(52.4 \%)$. About $49.6 \%$ of the females had left breast cancer only $9.7 \%$ had bilateral disease. Majority of the patients had invasive ductal carcinoma (IDC, 80.2\%), followed by invasive lobular carcinoma (ILC, 14.1\%), not other- wise specified (NOS, $4 \%$ ), and only $1.6 \%$ had mixed type. More than half of the patients had tumour grade II (55.6\%), $77.4 \%$ had tumour size greater than and equal to $2 \mathrm{~cm}$, and $43.1 \%$ of them had lymph node status as N2 (Table I).

Table I: Descriptive statistics of study subjects $(n=248)$.

\begin{tabular}{|c|c|c|}
\hline Variables & Mean & SD \\
\hline \multirow[t]{2}{*}{ Age (years) } & 47.88 & 12.585 \\
\hline & $\mathrm{n}$ & $\%$ \\
\hline \multicolumn{3}{|l|}{ Marital status } \\
\hline Married & 204 & 82.3 \\
\hline Unmarried & 23 & 9.3 \\
\hline Widow & 21 & 8.5 \\
\hline \multicolumn{3}{|c|}{ Employment status } \\
\hline Unemployed & 229 & 92.3 \\
\hline Employed & 19 & 7.7 \\
\hline \multicolumn{3}{|l|}{ Menopausal status } \\
\hline Pre-menopausal & 130 & 52.4 \\
\hline Post-menopausal & 118 & 47.6 \\
\hline \multicolumn{3}{|c|}{ Family history of breast cancer } \\
\hline Negative & 219 & 88.3 \\
\hline Positive & 29 & 11.7 \\
\hline \multicolumn{3}{|l|}{ Laterality } \\
\hline Right & 101 & 40.7 \\
\hline Bilateral & 24 & 9.7 \\
\hline Left & 123 & 49.6 \\
\hline \multicolumn{3}{|l|}{ Histology } \\
\hline IDC & 199 & 80.2 \\
\hline ILC & 35 & 14.1 \\
\hline NOS & 10 & 4 \\
\hline Mixed & 4 & 1.6 \\
\hline \multicolumn{3}{|l|}{ Grade } \\
\hline I & 15 & 6.0 \\
\hline II & 138 & 55.6 \\
\hline III & 95 & 38.3 \\
\hline \multicolumn{3}{|l|}{ Tumour size } \\
\hline$<2 \mathrm{~cm}$ & 56 & 22.6 \\
\hline$\geq 2 \mathrm{~cm}$ & 192 & 77.4 \\
\hline \multicolumn{3}{|l|}{ Lymph node status } \\
\hline No & 18 & 7.3 \\
\hline N1 & 105 & 42.3 \\
\hline $\mathrm{NII}$ & 107 & 43.1 \\
\hline $\mathrm{NIII}$ & 18 & 7.3 \\
\hline
\end{tabular}

The results of immunohistochemistry (IHC) showed that $82.7 \%$ of the tumours were E-cadherin positive, estrogen receptor (ER) positive status was found in $65.7 \%$, progesterone recptor (PR) positive status was found in $62.9 \%$ and positive human epidermal growth factor receptor 2 (HER-2) expression was found in $29.4 \%$ of the patients (Figure1).

There was astatistically significant relationship between E-Cadherin expression and age of the female $(p=0.003)$. Majority of the females were in age group 35-60 years and the proportion of females was significantly higher in positive expression (66.8\%) than negative expression (58.1\%).

The relationship between menopausal status and E-Cadherin expression was statistically significant $(p=0.028)$. Majority of the females, who had positive E-cadherin, were pre-menopausal (55.6\%). About $67.8 \%$ of the patients had positive E-cadherin expression, who had negative HER-2 status; and statistically significant association was found between E-cadherin expression and HER-2 ( $p=0.037)$. The statistically significant 
association was also found between E-cadherin and histological type of tumour, grade and size of tumour ( $p<0.05$, Tablell).

Table II: Association of E-cadherine expression with hormonal receptors and otherfactors.

\begin{tabular}{|c|c|c|c|}
\hline \multirow[b]{2}{*}{ Variables } & \multicolumn{2}{|l|}{ E-cadherin } & \multirow[b]{2}{*}{ p-value } \\
\hline & $\begin{array}{l}\text { Negative } \\
(n=43)\end{array}$ & Positive $(n=205)$ & \\
\hline \multicolumn{4}{|l|}{ Age groups } \\
\hline$<35$ years & $4(9.3 \%)$ & $42(20.5 \%)$ & \\
\hline $35-60$ years & $25(58.1 \%)$ & $137(66.8 \%)$ & \\
\hline$>60$ years & $14(32.6 \%)$ & $26(12.7 \%)$ & \\
\hline \multicolumn{4}{|c|}{ Menopausal status } \\
\hline Pre-menopausal & $16(37.2 \%)$ & $114(55.6 \%)$ & \multirow{2}{*}{0.028} \\
\hline Post-menopausal & $27(62.8 \%)$ & $91(44.4 \%)$ & \\
\hline \multicolumn{4}{|l|}{ ER } \\
\hline Negative & $14(32.6 \%)$ & $71(34.6 \%)$ & \multirow{2}{*}{0.794} \\
\hline Positive & $29(67.4 \%)$ & $134(65.4 \%)$ & \\
\hline \multicolumn{4}{|l|}{ PR } \\
\hline Negative & $17(39.5 \%)$ & $75(36.6 \%)$ & \multirow{2}{*}{0.716} \\
\hline Positive & $26(60.5 \%)$ & $130(63.4 \%)$ & \\
\hline \multicolumn{4}{|l|}{ HER 2} \\
\hline Negative & $36(83.7 \%)$ & $139(67.8 \%)$ & \multirow{2}{*}{0.037} \\
\hline Positive & $7(16.3 \%)$ & $66(32.2 \%)$ & \\
\hline \multicolumn{4}{|l|}{ Histological type } \\
\hline IDC & $21(48.8 \%)$ & $178(86.8 \%)$ & \multirow{4}{*}{$<0.001$} \\
\hline ILC & $18(41.9 \%)$ & $17(8.3 \%)$ & \\
\hline NOS & 0 & $10(4.9 \%)$ & \\
\hline MIXED & $4(9.3 \%)$ & 0 & \\
\hline \multicolumn{4}{|l|}{ Tumour grade } \\
\hline I & $7(16.3 \%)$ & $8(3.9 \%)$ & \multirow{3}{*}{$<0.001$} \\
\hline II & $30(69.7 \%)$ & $108(52.7 \%)$ & \\
\hline III & $6(14 \%)$ & $89(43.4 \%)$ & \\
\hline \multicolumn{4}{|l|}{ Tumour size } \\
\hline$<2 \mathrm{~cm}$ & $20(46.5 \%)$ & $36(17.6 \%)$ & \multirow{2}{*}{$<0.001$} \\
\hline$\geq 2 \mathrm{~cm}$ & $23(53.5 \%)$ & $169(82.4 \%)$ & \\
\hline \multicolumn{4}{|c|}{ Lymph node status } \\
\hline No & $4(9.3 \%)$ & $14(6.8 \%)$ & \multirow{4}{*}{0.235} \\
\hline N1 & $19(44.2 \%)$ & $86(42 \%)$ & \\
\hline N2 & $20(46.5 \%)$ & $87(42.4 \%)$ & \\
\hline N3 & 0 & $18(8.8 \%)$ & \\
\hline
\end{tabular}

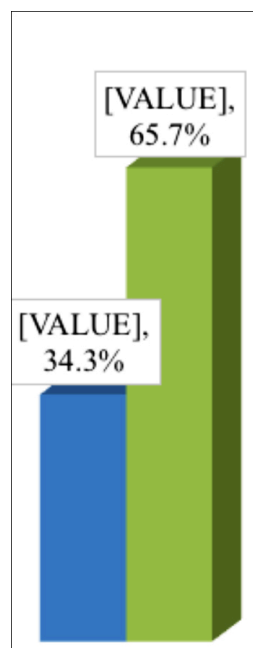

ER

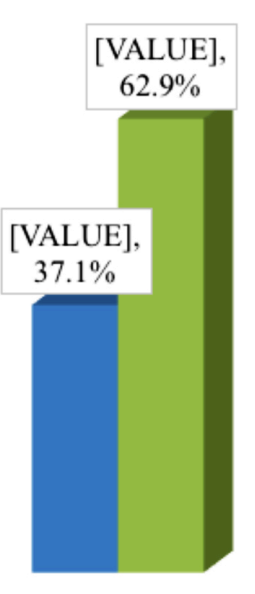

PR

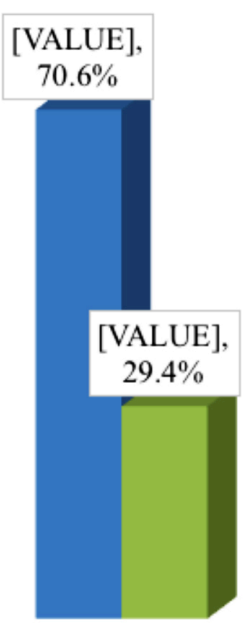

HER 2
- Negative Positive

Figure 1: Status of hormonal receptors.

\section{DISCUSSION}

The study results reflect the different socio-demographic features of patients of breast cancer. It showed that the mean age of the females with breast cancer was $47.88 \pm 12.58$ years; and almost half of the females had not reached to their menopause. However, in an Indian survey, the mean age of menopause women was found to be 46.2 years in Indian populace and 51 years in western population. ${ }^{15}$ The current study results also found that E-cadherin expression is positively associated with age of the females and menopausal status. The findings are in complete disagreement with the study suggesting no statistical significant association exists between E-cadherin expression and age of females or their menopausal status. ${ }^{16,17}$ The females, who were recruited in the present study, were $92.3 \%$ unemployed because of cultural factors, and majority of women stay at home as compared to the West.

The majority of the patients had invasive ductal carcinoma followed by invasive lobularcarcinoma. Breastcancer's progression and capacity to invade and metastasise to distant sites is strongly associated with the loss of E-cadherin. ${ }^{18}$ It has been postulated that loss of E-cadherin expression is an early gatekeeper event in in situ lobular breast cancer and a precursor of invasive lobular breast cancer. ${ }^{19,20}$ Inactivating mutations in the $\mathrm{CDH} 1$ gene have been frequently described and can explain a great proportion of invasive lobular breast cancer cases. In a subsequent study, Berx and colleagues found somatic mutations of the E-cadherin gene at a comparable frequency, $56 \%$ ( 23 of 41 ) of lobular carcinoma cases, showing E-cadherin mutations. ${ }^{21}$ This high frequency of $\mathrm{CDH} 1$ mutations in breast cancer was not reported in all studies. Specifically, among the 23 mutations identified by Berx and colleagues, ${ }^{21}$ combination with $\mathrm{LOH}$ of the wild type $\mathrm{CDH} 1$ were found locus. These data were further validated by Huiping and colleagues, ${ }^{22}$ who detected $\mathrm{LOH}$ at $16 \mathrm{q} 22.1$ in all of the lobular breast tumours examined by their study. Currently, it is well established that $50 \%$ of invasive lobular carcinomas show $\mathrm{LOH}$, which is determinant for protein dysfunction and loss of expression.

The current study results showed 82.7 of the tumours were Ecadherin positive, estrogen receptor (ER) positive status was found in $65.7 \%$, progesterone receptor (PR) positive status was found in $62.9 \%$ and positive human epidermal growth factor receptor 2 (HER-2) expression was found in $29.4 \%$ of the patients. Horne et al. stratified estrogen receptor (ER) status and histological subtype among low E-cadherin patients and concluded that low expression of E-cadherin suggested low grade breast cancer and associated with tumour size of $>2 \mathrm{~cm}$ having lobular histology and HER2-negative. ${ }^{23}$

Singhai R et al. found a correlation between E-cadherin loss and invasive lobular carcinoma. However, he also found that no correlation existed among any prognostic variables of tumor. Diagnosis of invasive lobular carcinoma was made on the basis of negative E-cadherin stain having $88.1 \%$ sensitivity and $97.7 \%$ specificity. Moreover, E-cadherin expression was positive in patients diagnosed with tubulo-lobular carcinomas. ${ }^{24}$ 
Yang Li etal. claimed that loss of E-cadherin was associated positively with metastasis of lymph node. ${ }^{12}$ Fulgaet al. concluded that E-cadherin is highly expressed in primary breast cancer sites as compared to metastatic sites. ${ }^{25}$

The current study results also found that E-cadherin expression is associated with negative HER-2 status. The statistically significant association was also found between E-cadherin and histological type of tumour, grade and size of tumour $(p<0.05)$. The findings are in concordance with the study conducted by ParkerCetal. ${ }^{26}$

The present study had its time constraints, therefore, more indepth studies should be carried out. The expression of E-cadherin is yet to be studied in Asian population so that prognosis of breast carcinoma can be made easy. In a systemic review, odds ratio revealed strong association of E-cadherin expression with histopathological grading of tumours, tumour staging, tumour size, lymph node status, and hormone receptorstatus. ${ }^{5}$

\section{CONCLUSION}

There is a significant association between E-cadherin expression and hormone receptor status, HER2-neu, menopausal status, age of patients, grade of tumour and size of tumour. The present study had its time constraints, therefore, more in-depth studies should be carried out.

\section{ETHICAL APPROVAL:}

The Ethical Review Committee approval was taken before conduction of the study.

\section{PATIENTS' CONSENT:}

Informed consents from all the eligible patients were obtained before collection of data.

\section{CONFLICT OF INTEREST:}

The authors declared no conflict of interest.

\section{AUTHORS' CONTRIBUTION:}

AHA: Did the majority of manuscript writing, acquired all data by following up patients, and performed data analysis.

$\mathrm{GH}$ : Contributed to design of the work, final approval of the version to be published.

KA: Contributed to design of work data collection.

MH, PK, RI: Data collection and interpretation.

\section{REFERENCES}

1. Luo SL, Xie YG, Li Z, Ma JH, Xu X. E-cadherin expression and prognosis of oral cancer: A meta-analysis. Tumor Biology 2014; 35(6):5533-7.doi: 10.1007/s13277-0141728-0.

2. Ren ZH, Xu JL, Li B, Fan TF, Ji T, Zhang CP. Elective versus therapeutic neck dissection in node-negative oral cancer: Evidence from five randomized controlled trials. Oral Oncol 2015; 51(11):976-81.doi: 10.1016/j.oraloncology. 2015.08.009.

3. Ferlay J, Soerjomataram I, Dikshit R, Eser S, Mathers C, Rebelo $M$, et al. Cancer incidence and mortality worldwide: Sources, methods and major patterns in GLOBOCAN 2012.
International journal of cancer 2015; 136(5):E359-E86.doi: 10.1002/ijc.29210.

4. Xu C, Wei Q, Guo J, Zhou JC, Mei J, Jiang ZN, et al. FOXA1 expression significantly predict response to chemotherapy in estrogen receptor-positive breast cancer patients. Annal Surg Oncol 2015; 22(6):2034-9.doi: 10.1245/s10434-0144313-2.

5. Li Z, Yin S, Zhang L, Liu W, Chen B. Prognostic value of reduced $\mathrm{E}$-cadherin expression in breast cancer: A metaanalysis. Oncotarget 2017; 8(10):16445.doi: 10.18632/ oncotarget.14860.

6. Berx G, Van Roy F. The E-cadherin/catenin complex: an important gatekeeper in breast cancer tumorigenesis and malignant progression. Breast Cancer Research 2001; 3(5):289.doi: 10.1186/bcr309.

7. Berman AT, Thukral AD, Hwang WT, Solin LJ, Vapiwala N. Incidence and patterns of distant metastases for patients with early-stage breast cancer after breast conservation treatment. Clinical breast cancer 2013;13(2):88-94.doi: 10.1016/j.clbc.2012.11.001

8. Paredes J, Figueiredo J, Albergaria A, Oliveira P, Carvalho J, Ribeiro AS, et al. Epithelial E-and P-cadherins: role and clinical significance in cancer. Biochim Biophys Acta 2012; 1826(2):297-311.doi: 10.1016/j. bbcan.2012.05.002.

9. Rakha EA, Reis-Filho JS, Ellis IO. Combinatorial biomarker expression in breast cancer. Breast Cancer Res Treatment 2010;120(2):293-308.doi: 10.1007/ s10549010-0746-x.

10. Donegan WL. Tumor-related prognostic factors for breast cancer. CA Cancer Clin 1997; 47(1):28-51.doi: 10.3322/ canjclin.47.1.28.

11. Rakha E, Abd El Rehim D, Pinder S, Lewis S, Ellis I. Ecadherin expression in invasive non-lobular carcinoma of the breast and its prognostic significance. Histopathol 2005; 46(6):685-93.doi: 10.1111/j.1365-2559.2005. 02156.x.

12. Yang L, Wang XW, Zhu LP, Wang HL, Wang B, Zhao Q, et al. Significance and prognosis of epithelial-cadherin expression in invasive breast carcinoma. Oncol Letters 2018; 16(2):1659-65.doi: 10.3892/ol.2018.8836.

13. Kashiwagi S, Yashiro M, Takashima T, Nomura S, Noda S, Kawajiri $\mathrm{H}$, et al. Significance of $\mathrm{E}$-cadherin expression in triple-negative breast cancer. $\mathrm{Br} J$ Cancer 2010; 103(2):249-55.doi: 10.1038/sj.bjc.6605735.

14. Tang D, Xu S, Zhang Q, Zhao W. The expression and clinical significance of the androgen receptor and Ecadherin in triple-negative breast cancer. Med Oncol 2012; 29(2):526-33.doi: 10.1007/s12032-011-9948-2.

15. Ahuja M. Age of menopause and determinants of menopause age: A PAN India survey by IMS. J Mid-life Health 2016;7(3):126.doi: 10.4103/0976-7800.191012.

16. IMemni H, Macherki Y, Klayech Z, Ben-Haj-Ayed A, Farhat $\mathrm{K}$, Remadi $\mathrm{Y}$, et al. E-cadherin genetic variants predict survival outcome in breast cancer patients. J Trans Med 2016; 14(1):320.doi: 10.1186/s12967-016-1077-4.

17. Salati A, Akbari ME, Nafissi N, Noorian S, Mahdavi SR, Mirzaei HR, et al. Comparison of Outcome between Invasive Lobular Carcinoma (ILC) and Invasive Ductal Carcinoma 
(IDC) Patients Treating with Breast Conserving Surgery (BCS) and Radical Dose of Intraoperative Electron Radiotherapy (IOERT). Int J Cancer Management 2018; 11(11).

18. Corso G, Figueiredo J, De Angelis SP, Corso F, Girardi A, Pereira J, et al. E-cadherin deregulation in breast cancer. J Cell Molecul Med 2020; 24(11):5930-6.doi: 10.1111/ jcmm.15140.

19. Hunt NC, Douglas-Jones AG, Jasani B, Morgan JM, Pignatelli $M$. Loss of E-cadherin expression associated with lymph node metastases in small breast carcinomas. Virchows Archiv 1997; 430(4):285-9.doi: 10.1007/BF01092751.

20. Oka H, Shiozaki H, Kobayashi K, Inoue M, Tahara H, Kobayashi $\mathrm{T}$, et al. Expression of E-cadherin cell adhesion molecules in human breast cancer tissues and its relationship to metastasis. Cancer Res 1993; 53(7): 1696-701.

21. Berx G, Cleton-Jansen AM, Nollet F, de Leeuw WJ, van de Vijver M, Cornelisse C, et al. E-cadherin is a tumour/ invasion suppressor gene mutated in human lobular breast cancers. EMBO J 1995; 14(24):6107-15.

22. Huiping C, Sigurgeirsdottir JR, Jonasson JG, Eiriksdottir G,
Johannsdottir JT, Egilsson V, et al. Chromosome alterations and E-cadherin gene mutations in human lobular breast cancer. Br J Cancer 1999; 81(7):1103-10. doi: 10.1038/sj. bjc. 6690815.

23. Horne HN, Oh H, Sherman ME, Palakal M, Hewitt SM, Schmidt MK, et al. E-cadherin breast tumor expression, risk factors and survival: Pooled analysis of 5,933 cases from 12 studies in the Breast Cancer Association Consortium. SciRep 2018; 8(1):6574. doi: 10.1038/s41598018-23733-4.

24. Singhai R, Patil VW, Jaiswal SR, Patil SD, Tayade MB, Patil AV. E-Cadherin as a diagnostic biomarker in breast cancer. N Am J Med Sci 2011; 3(5):227. doi: 10.4297/najms. 2011.3227.

25. Fulga V, Rudico L, Balica AR, Cimpean AM, Saptefrati L, Margan MM, et al. Differential expression of E-cadherin in primary breast cancer and corresponding lymph node metastases. Anticancer Res 2015;35(2):759-65.

26. Parker C, Rampaul R, Pinder S, Bell J, Wencyk P, Blamey R et al. E-cadherin as a prognostic indicator in primary breast cancer. Br J Cancer 2001; 85(12):1958. doi: 10.1054/ bjoc.2001.2178. 